\title{
PROFESSOR YURIĬ PETROVICH STUDNEV (ON THE 80TH ANNIVERSARY OF HIS BIRTH)
}

\author{
A. I. MOTSA
}

Abstract. A brief account of scientific activities of Professor Yu. P. Studnev at Uzhgorod State University is given.

Yurii Petrovich Studnev was an outstanding scholar and teacher, one of the most authoritative personalities among the teaching staff of the Faculty of Mathematics at Uzhgorod State University in 1953-1998. An unpretentious, congenitally gifted, intelligent, delicate teacher and instructor, who had a deep feeling of beauty and harmony; a democratic and benevolent chair of the Department of Mathematical Analysis; a highly educated and erudite scholar not only in mathematical but also in applied sciences,this is how he is remembered by everybody who attended his lectures, worked under his guidance, or communicated with him.

1. Yu. P. Studnev was born on June 17, 1923, in the town of Bandare Gaz (Iran), into the family of an employee of a Soviet Trade Delegation. Since 1926 the family lived in various cities of the Soviet Union (Baku, Penza, Frunze, Przheval'sk, again Frunze, Stalingrad, etc.) where his father was assigned to work. In 1940, after graduating from a 10-year secondary school, Studnev entered the Central-Asian State University (in the city of Tashkent). A serious illness of his father and the need to help an elder sister who was studying at the Moscow Textile Institute made Studnev interrupt his university studies and go to work.

The war started. Studnev was first exempted from military service due to weak sight. But in January 1944 he was pronounced fit for noncombatant service and mobilized to work at a military registration and enlistment office of the Zhitomyr district. After discharge in August 1945 Yuriü Petrovich entered L'viv State University. He brilliantly graduated from this university in 1950 and obtained a degree in mathematics. Immediately upon his graduation he was admitted for postgraduate studies, which were successfully completed by the defense of a dissertation work for the academic degree of the Candidate of Science in Physics and Mathematics (a Ph.D. equivalent) on September 26, 1953. After he had been appointed a Senior Instructor to act as the Chair of the Department of Mathematical Analysis, he worked at Uzhgorod State University till the very last day of his life on April 23, 1998.

Several generations made their way under his supervision from a first-year student to a specialist in mathematics. Future Doctors of Sciences were among the students of the Faculty of Physics and Mathematics at Uzhgorod State University: V. Yu. Slyvka, now the rector of Uzhgorod National University, Corresponding Member of the National Academy of Sciences of Ukraine V. I. Fushchych, Professors I. Yu. Babych, M. D. Babych, S. Yu. Babych, L. F. Barannyk, A. F. Barannyk, A. A. Bovdi, K. Buzashi, F. G. Vashchuk, I. G. Golovach, P. M. Gudyvok, D. V. Gusak, G. B. Karpilovs'ky, A. U. Klymyk,

2000 Mathematics Subject Classification. Primary 01A70. 


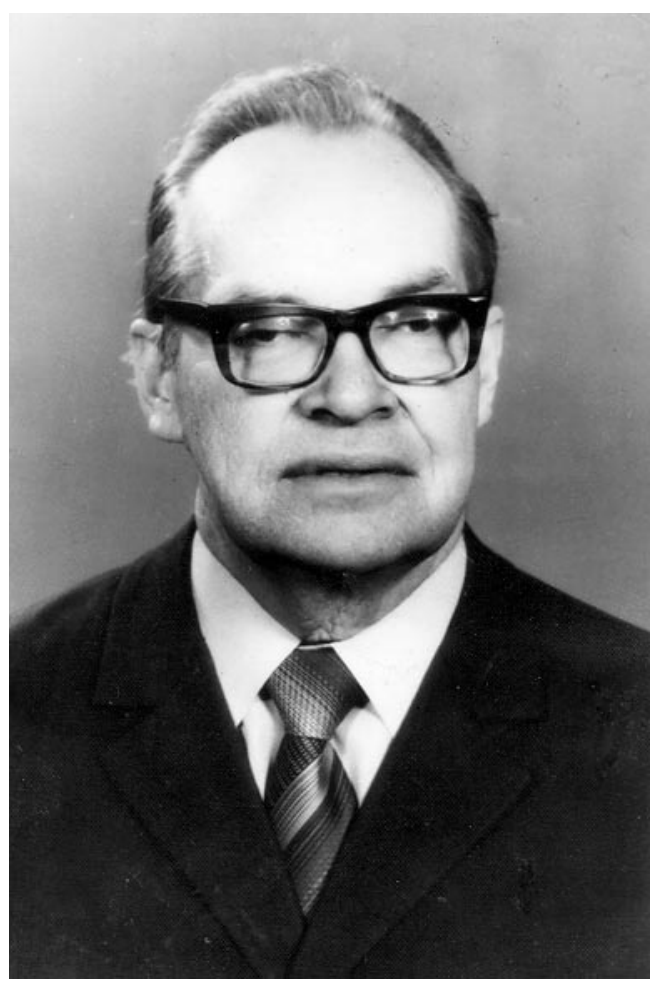

Yuriı̌ Petrovich Studnev (1923-1998)

O. I. Likhtman, V. V. Marynets', I. I. Markush, M. I. Ronto, Yu. Yu. Chervak among others, and a large group of Candidates of Science, Associate Professors. The majority of the teaching staff at the Department of Mathematical Analysis created by Yuriu Petrovich was and still is formed by his disciples: V. I. Dobosh, Yu. I. Ignat, Yu. M. Orban, V. O. Peten'ko, P. V. Slyusarchuk, D. I. Lyalina, M. I. Nemesh.

2. The main directions of Studnev's research were determined by his doctoral supervisor, the member of the Academy of Sciences of Ukraine, Professor B. V. Gnedenko, and were devoted to different types of convergence to the normal law, estimates of the convergence rate in limit theorems of probability theory, generalizations of limit theorems, problems in probability theory related to nonmonotone distribution functions, quasi-probability schemes and their applications, in particular, to the theory of ordinary differential equations and partial differential equations.

The first paper by Studnev [1] dealt with a study of regularities appearing in the comparison of empiric distribution functions, obtained as a result of two series of independent trials, of random variables having the same continuous distribution of probabilities.

The Ph.D. thesis by Studnev [2] contains a number of interesting results related to the topics covered in the well-known monograph by Gnedenko and Kolmogorov, "Limit theorems of sums of independent random variables", published in 1949. He obtained in [2] the order of decay of the remainder term for the convergence of the distribution functions of normalized sums of independent identically distributed random variables to the normal law $\Phi(x)$. He confirmed that relaxing the assumptions imposed on the common distribution function of terms causes a slowing down of the rate of convergence to the normal law. 
3. An early period of Studnev's creative work is presented by the papers [3], 4], and [6]-13] dealing with the problem of the asymptotic behavior of accompanying laws and the order with which distribution functions of sums of independent random variables approach the corresponding infinitely divisible laws in different cases of the Lyapunov theorem. He investigated [6] the role of Lindeberg's condition in the study of the rate of convergence of the distribution functions

$$
\Phi_{n}(x)=\mathrm{P}\left\{\frac{1}{B_{n}}\left(\xi_{1}+\cdots+\xi_{n}\right)<x\right\}
$$

of normalized sums of independent random variables $\xi_{1}, \xi_{2}, \ldots, \xi_{n}, \ldots$ (with distribution functions $F_{n}(x), n \geq 1$, and variance $\operatorname{Var} \xi_{n}=\sigma_{n}^{2}, B_{n}^{2}=\sigma_{1}^{2}+\cdots+\sigma_{n}^{2}$ for $n \geq 1$ ) to the normal law.

In the 1960s, Studnev continued successful work on sharpening the estimates for the rate of convergence to the normal law of the distribution functions of normalized sums of mutually independent random variables [16, [17, [19]-27]. In the paper [21, he made the results of [6] more precise. He showed that the following estimate holds under the assumptions of the central limit theorem:

$$
\sup _{x}\left|\Phi_{n}(x)-\Phi(x)\right| \leq C \frac{1}{B_{n}} \int_{0}^{B_{n}} L_{n}(z) d z,
$$

where $C$ is an absolute constant, and

$$
L_{n}(x)=\frac{1}{B_{n}^{2}} \sum_{k=1}^{n} \int_{|z| \geq x} z^{2} d F_{k}(z) .
$$

Among the papers published by Studnev in the 1960s, the results on the rate of convergence of the functions $F_{n}(x)=F^{* n}\left(B_{n} x+A_{n}\right)$ to a stable law $G_{\alpha}(x)$, where the centering coefficients $A_{n}$ and the normalizing coefficients $B_{n}=a n^{1 / \alpha}$ are chosen in an appropriate way, deserve a special attention.

4. A major contribution of Studnev to probability theory consists in working out the concepts of negative probability and quasi-measure and establishing fundamental results in this area.

Applied problems had been attracting Studnev's attention from the very beginning of his research. He became interested in the mathematical problem on the possible convergence of convolutions of functions of bounded total variation on $(-\infty, \infty)$ that differ from classical distribution functions only by their nonmonotonic character, to functions whose Fourier-Stieltjes transform is of the type

$$
\exp \left\{\frac{-t^{2 q}}{(2 q) !}\right\}, \quad q \geq 1 .
$$

This problem was formulated by Gnedenko in 1952 at a seminar on probability theory in Kiev. It was related to the construction of multicascade amplifiers at the Institute of Telegraphic Communication of the Academy of Sciences of the USSR.

In the papers [5, 14, 15, 18, Studnev studied the behavior of convolutions of functions of bounded variation where the number of components is increasing infinitely, as well as some limit theorems for nonmonotone distributions functions.

In the 1970s, Studnev's attention was drawn to theoretical and applied aspects of applications of quasi-probability models to the solution of various problems in mathematics. In particular, an advanced quasi-probability theory enabled Studnev to consider 
from a general point of view some classification problems related to linear partial differential equations of an arbitrary finite order and to sharpen the concept of the "order of a differential equation" itself.

5. In the 1980s Studnev studied operator calculus based on convolutions of functions (continuous case) and convolutions of sequences (discrete case), which made it possible to use an algebraic approach to the solution of problems for linear (ordinary and partial) differential equations as well as finite-difference equations with varying coefficients.

In the second half of the 1980s and in the 1990s, Studnev continued his work on classification problems in the theory of partial differential equations. For example, in the studies of parabolic differential equations that are $s$-regular in the sense of G. E. Shilov it was established that, under certain conditions, the solutions of these equations are weakly stable multidimensional probability laws that constitute a new class of stable laws generated by the so-called mixed homogeneity forms. Combining the probability and operator methods in the theory of differential equations and finite-difference equations, he proposed 32 a new number-theoretical approach to the classification of partial differential equations.

A fruitful idea of Studnev was to generalize the concept of "derivative of a function" 34, 35 and to introduce "stochastic" elements into the theory of differential equations, namely into the notions of "derivative", "integral", "convolution", etc.

Studnev developed the technique of generalized derivatives and generalized integrals, which enabled him to carry out some ideas of randomization of differential and integrodifferential equations and to obtain new stochastic processes together with convenient means for their study. He proposed a theory of generalized (Einstein-type) summation of independent random variables that provided a new form of space-bounded stochastic processes as well as established a link to differential equations of a special form.

\section{Papers by Yu. P. StudneV}

1. B. V. Gnedenko and Yu. P. Studnev, Comparison of the effectiveness of several methods of testing homogeneity of statistical material, Dopovidi Akad. Nauk. Ukrain. RSR 5 (1952), 359363. (Ukrainian) MR 15:544c

2. Yu. P. Studnev, On Convergence to the Normal Law, Dissertation for the degree of Candidate of Phys.-Mathemat. Sciences, L'vov, 1953. (Russian)

3. Yu. P. Studnev, On the behaviour of the remainder term under the conditions of the Lyapunov theorem, Uzhgorod. Gos. Univ. Nauchn. Zap. Ser. Khim. Fiz. Mat. 18 (1957), 183-189. (Russian) MR 20:3585

4. Yu. P. Studnev, On the asymptotic behaviour of accompanying laws, Dokl. Soobshch. Uzhgorod. Univ. Ser. Fiz. Mat. Khim. 1 (1957), 6. (Russian)

5. Yu. P. Studnev, On convolutions of functions of bounded variation, Dokl. Soobshch. Uzhgorod. Univ. Ser. Fiz. Mat. Khim. 2, 1958. (Russian)

6. Yu. P. Studnev, On the role of Lindeberg's conditions, Dopovidi Akad. Nauk Ukrain. RSR 3 (1958), 239-242. (Ukrainian) MR 20:6147

7. Yu. P. Studnev, An approximation to the distribution of sums by infinitely divisible laws, Teor. Veroyatnost. i Primenen. 5 (1960), no. 4, 465-469; English transl. in Theory Probab. Appl. 5 (1960), 421-424. MR 24:A3685

8. Yu. P. Studnev, On approximation of the distribution functions of sums of independent random variables by infinitely divisible laws, Dokl. Soobshch. Uzhgorod. Univ. Ser. Fiz. Mat. 3 (1960), 68-69. (Russian)

9. Yu. P. Studnev, On the rate of convergence to the normal law in the case of infinite variances, Dokl. Soobshch. Uzhgorod. Univ. Ser. Fiz. Mat. 3 (1960), 70-71. (Russian)

10. Yu. P. Studnev, On a property of accompanying laws, Proc. All-Union Conf. on Probab. Theory and Mathemat. Statist., Acad. Sci. Arm. SSR, Erevan, 1960, pp. 33-34. (Russian)

11. Yu. P. Studnev, On the convergence in mean to a normal law, Dokl. Soobshch. Uzhgorod. Univ. Ser. Fiz. Mat. 4 (1961), 96-97. (Russian) 
12. Yu. P. Studnev, Some limit theorems for densities, Dokl. Soobshch. Uzhgorod. Univ. Ser. Fiz. Mat. 4 (1961), 98-100. (Russian)

13. Yu. P. Studnev, On a modification of the Lévy-Khintchine theorem and its role in the estimation of the convergence rate, Dokl. Soobshch. Uzhgorod. Univ. Ser. Fiz. Mat. Istor. 6 (1962), 84-85. (Russian)

14. Yu. P. Studnev, Some limit theorems for nonmonotone distribution functions, Dokl. Soobshch. Uzhgorod. Univ. Ser. Fiz. Mat. Istor. 5 (1962), 82-84. (Russian)

15. Yu. P. Studnev, Limit theorems for nonmonotone distribution functions, Abstracts Comm. All-Union Colloquium on Limit Theorems in Probab. Theory, Fergana, 1962. (Russian) MR 28:632

16. Yu. P. Studnev, On a universal estimate, Abstracts Comm. All-Union Colloquium on Limit Theorems in Probab. Theory, Fergana, 1962, p. 36. (Russian) MR 28:632

17. Yu. P. Studnev, On a universal estimate, Limit Theorems in Probability Theory, Collection of papers, Tashkent, 1962, pp. 131-135. (Russian)

18. Yu. P. Studnev, On a limit theorem for nonmonotone distribution functions, Abstracts Comm. 17th Sci. Conf. Uzhgorod Univ., Uzhgorod, 1963, pp. 53-54. (Russian)

19. Yu. P. Studnev, A remark on Katz-Petrov theorem, Teor. Veroyatnost. i Primenen. 10 (1965), no. 4, 751-753; English transl. in Theory Probab. Appl. 10 (1965), 682-684. MR 32:8392

20. Yu. P. Studnev, On the rate of convergence toward stable distribution laws, Dokl. Akad. Nauk SSSR 167 (1966), no. 1, 34-37; English transl. in Soviet Math. Dokl. 7 (1966), 332-335. MR 33:6676

21. Yu. P. Studnev, On universal estimates of the rate of convergence to stable laws, Abstracts of Short Comm. of the 6th Internat. Math. Congress, Section 11, Moscow, 1966, p. 53. (Russian) MR 38:960

22. D. I. Lyalina and Yu. P. Studnev, Some generalizations of limit theorems of probability theory for lattice distributions, "Naukova Dumka", Kiev, 1966 pp. 512-517. (Russian) MR 33:759

23. Yu. P. Studnev and Yu. I. Ignat, Refinement of the central limit theorem and of its global version, Teor. Veroyatnost. i Primenen. 12 (1967), no. 3, 562-567; English transl. in Theory Probab. Appl. 12 (1967), 508-512. MR 35:6189

24. Yu. P. Studnev, Some generalizations of limit theorems in probability theory, Teor. Veroyatnost. i Primenen. 12 (1967), no. 4, 729-734; English transl. in Theor. Probability Appl. 12 (1967), 668-672. MR 37:2303

25. Yu. P. Studnev, Certain properties of the accompanying laws for symmetric distribution functions, Teor. Veroyatnost. i Primenen. 13 (1968), no. 4, 742-745; English transl. in Theor. Probability Appl. 13 (1968), 701-703. MR 39:3553

26. Yu. P. Studnev, A certain form of the estimate of the rate of convergence to the normal law, Ukrain. Mat. Zh. 20 (1968), no. 2, 281-285. (Russian) MR 36:7186

27. Yu. P. Studnev, On some generalizations of limit theorems in probability theory, Abstracts Comm., 2nd Econom.-Cyber. Conf. "Economical and Mathematical Methods in Regional Forecasting and Modeling of Territorial Economic Systems", Kiev, 1968, p. 10. (Russian)

28. Yu. P. Studnev, The theory of infinitely divisible laws in the class B. I, Teor. Veroyatnost. i Mat. Statist. 2 (1970), 183-192; English transl. in Theor. Probab. Math. Statist. 2 (1971), 187-196. MR 46:2713

29. Yu. P. Studnev, On the Convolutions of Functions of Bounded Variation, Dissertation for the degree of Doctor of Phys.-Math. Sciences, Kiev, 1971. (Russian)

30. Yu. M. Orban and Yu. P. Studnev, Airy and Fresnel type functions as limit laws for convolutions of functions of bounded variation, Ukrain. Mat. Zh. 25 (1973), no. 3, 323-331; English transl. in Ukrainian Math. J. 25 (1974), 255-262. MR 48:11901

31. V. A. Peten'ko and Yu. P. Studnev, An analog of a two-dimensional local limit theorem, Ukrain. Math. Zh. 29 (1977), no. 4, 541-549; English transl. in Ukrainian Math. J. 29 (1978), no. 4, 415-421. MR 56:9649

32. Yu. P. Studnev, On a number theoretical approach to the classification of partial differential equations, Abstr. Comm. of All-Union Conf. "New Approaches to the Solution of Differential Equations", Moscow, 1987, 110-111. (Russian)

33. Yu. I. Ignat and Yu. P. Studnev, A local limit theorem for discrete quasi-probability distributions, Teor. Veroyatnost. i Primenen. 37 (1992), no. 4, 807-808. (Russian) 
34. Yu. P. Studnev, On a generalization in the theory of stochastic integrals, Abstracts Comm. Sci. Conf. of Teaching Staff of Math. Faculty of Uzhgorod. State Univ., Uzhgorod, 1994, p. 1. (Russian)

35. Yu. P. Studnev, Elements of $(\varphi, \psi)$ analysis, Abstracts Comm. Sci. Conf. of Teaching Staff of Math. Faculty of Uzhgorod. State Univ., Uzhgorod, 1995. (Russian)

Department of Mathematical Analysis, Uzhgorod National University, 46 Pidgirna Street, UZHGOROD, UKRAINE

Received 21/OCT/2002

Translated by V. ZAIATS 